Research Article

\title{
Experimental Investigation on the Tensile and Fracture Properties of Burst-Prone Coal under Quasistatic Condition
}

\author{
Shuang Gong $\mathbb{D}^{1,2,3}$ Zhen Wang, ${ }^{1,2,3}$ Lei Zhou $\mathbb{D}^{1,2,3}$ and Wen Wang ${ }^{1,3}$ \\ ${ }^{1}$ School of Energy Science and Engineering, Henan Polytechnic University, Jiaozuo 454000, China \\ ${ }^{2}$ Henan Key Laboratory for Green and Efficient Mining \& Comprehensive Utilization of Mineral Resources, \\ Jiaozuo 454000, China \\ ${ }^{3}$ Collaborative Innovation Center of Coal Work Safety, Jiaozuo 454000, Henan Province, China \\ Correspondence should be addressed to Shuang Gong; gongcumtb@126.com
}

Received 27 January 2021; Revised 10 February 2021; Accepted 19 February 2021; Published 26 February 2021

Academic Editor: Junfei Zhang

Copyright ( 2021 Shuang Gong et al. This is an open access article distributed under the Creative Commons Attribution License, which permits unrestricted use, distribution, and reproduction in any medium, provided the original work is properly cited.

\begin{abstract}
To study the tensile and fracture properties of the specimen under the quasistatic loading, the Brazilian disc splitting method and the notched semicircular bend (NSCB) method were used to test the tensile properties of coal specimens, and the fracture properties of NSCB specimens with different notch depths were tested and analyzed. The applicability of plane strain fracture toughness $K_{\mathrm{IC}}$ and $J$-integral fracture toughness in evaluating the fracture properties of coal specimens was discussed. The influence of notch depth on the fracture toughness measurement of the NSCB specimen was studied. Combined with the surface strain monitoring of specimens during loading and the industrial CT scanning image of damaged specimens, the deformation characteristics of coal specimen under loads and the distribution law of crack after failure were analyzed. The results show that the NSCB test is suitable for measuring the tensile strength of a coal specimen; when the dimensionless notch depth is $\beta=0.28$, the dispersion of plane strain fracture toughness $K_{\mathrm{IC}}$ of the NSCB specimen is the smallest. Besides, the plane strain fracture toughness of coal is obviously affected by the notch depth and dimensionless stress intensity factor. The $J$-integral fracture toughness can be used to effectively evaluate the fracture performance of specimens.
\end{abstract}

\section{Introduction}

The tensile and fracture properties of rock are of great significance for rock mass stability control [1], rock hydraulic/gas fracturing [2], and roadway roof support design [3, 4]. Many scholars have carried out extensive research on the mechanism of tunnel deformation instability and rock burst. Zhang et al. [5] established an energy integral model for the rockburstinducing area and a friction work calculation model for the plastic area. If the remaining energy after the coal seam is broken in the rockburst-inducing area is greater than the friction work required for the coal to burst out, then a rockburst accident will occur. Zhang et al. [6] also propose a robust classifier ensemble to predict squeezing conditions in rock tunnels. Seven individual machine-learning classifiers were aggregated using weighted voting methods to establish the classifier ensemble. In the research field of seepage and failure of rock mass, Ma et al. [7, 8] quantitatively analyzed the characteristics of water-sediment flow in rock fractures by computational fluid dynamics (CFD). Based on the two-phase flow theory, a resistance model of water-sediment flow in fractures was established and verified by a laboratory-scale test. Among these studies, the testing of relevant mechanical properties of coal rocks is critical. The accurate and effective parameter measurement of tensile and fracture properties of coal rock has always been a research hotspot in rock mechanics and mining engineering. At present, the determination methods for the tensile strength of rock materials in the laboratory mainly include the direct tensile test, the Brazilian disc splitting test, beam bending test, and semicircular bend test [9]. The direct tensile test is the most direct method to obtain the tensile strength of rock materials. However, the direct tensile test requires special fixtures, and the specimen processing is difficult [9]. In the Brazilian disc splitting test, the 
internal stress distribution of the specimen is complex, and the compressive stress on the specimen axis is 3 times the tensile stress [10], leading to the tendency of fracture failure for specimens. The rectangular beam three-point bending test [11] has good effect in the tensile strength test, but it is difficult to process raw coal into a rectangular beam specimen, and the specimen is easily damaged by the notch and grinding. In recent years, the semicircular bend test has been widely used to test the tensile properties of rock or asphalt due to its simple operation and specimen processing. However, there are few reports about the semicircular bend test of specimens.

To measure the fracture toughness of mode I rock materials, the International Society for Rock Mechanics (ISRM) recommends four types of specimens: short rod (SR), chevron bend (CB), cracked chevron notched Brazilian disc (CCNBD), and notched semicircular bend (NSCB) specimens [12]. Fowell et al. [13-15] compared SR, CB, and CCNBD specimens. It was found that there were many unfavorable factors in SR and CB tests, such as the lower load required for the specimen failure, larger core, complex loading system, and complicated preparation of short rod specimens; the test device and fixture required for CCNBD specimens were relatively simple, and $\mathrm{CCNBD}$ specimens were easier to prepare and can be used for the toughness test of various fracture modes. Kuruppu et al. [12, 16] believed that the NSCB test has the advantages of fewer specimens and simple loading device in testing mode I fracture toughness of rock materials under quasistatic loading. However, the analysis of crack propagation characteristics and the influence of notch depth in the fracture toughness test of rock materials using the NSCB specimens is still limited.

Besides, the NSCB testing method has been successfully applied to the fracture performance test of asphalt mixture $[17,18]$, mineral mixture [19], marble [20, 21], concrete [22], limestone [23], and other materials. However, there are relatively few experimental studies on the fracture toughness of coal specimens under the quasistatic condition. Coal is a complex heterogeneous anisotropic material, and the complex spatial distribution of its components and bedding increases the dispersion of NSCB test results for coal. Therefore, it is necessary to perform semicircular bend tests and NSCB tests to study its tensile and fracture properties.

In this paper, the quasistatic BD tests and SCB tests of specimens were carried out to compare the measured tensile strength, and then, the applicability of the NSCB method in measuring the tensile strength of specimens was analyzed. The fracture toughness of NSCB specimens with different notch depths was measured, and the influence of notch depth on the fracture toughness test results was studied. Combined with the surface strain monitoring of specimens under loads and CT scanning images of damaged specimens, the deformation and crack distribution characteristics of specimens under loads were analyzed.

\section{Specimen Preparation and Test Method}

2.1. Specimen Collection and Processing. The specimens, belonging to bituminous coal, were taken from the coal seam 11 of Xinzhouyao mine to the northeast of Datong coalfield, Shanxi Province. The moisture content of the specimen was $4.13 \%$, ash content was $2.04 \%$, volatile content was $25.81 \%$, fixed carbon content was $69.17 \%$, density was $1.301 \mathrm{~g} / \mathrm{cm}^{3}$, elastic modulus was $5.41 \mathrm{GPa}$, and Poisson's ratio was 0.24 . Table 1 shows the maceral composition of Datong coal. According to the Brazilian disc specimen preparation method recommended by ISRM [24], 15 disc specimens (4 of which were BD specimens for testing) of $\Phi 50 \mathrm{~mm} \times 25 \mathrm{~mm}$ were drilled parallel to the coal and rock bedding plane and processed. Within the angle of $40-50^{\circ}$ between the notch surface and the bedding surface of the disk specimen, 10 disc specimens were cut in half to form 20 semicircular SCB specimens. Then, 12 specimens were taken and slit perpendicular to the bottom surface at the center of the bottom; then, 3 groups of NSCB specimens with the notch width of $1 \mathrm{~mm}$ and the notch depth $a$ of $4 \mathrm{~mm}, 7 \mathrm{~mm}$, and $10 \mathrm{~mm}$, respectively, were taken. There were 4 specimens in each group. Table 2 shows the parameters of BD, SCB, and NSCB specimens.

ISRM suggests that when the NSCB method is used to test the mode I quasistatic fracture toughness of rock materials, the support point spacing $S$ and specimen diameter $D$ should be $0.5 \leq \mathrm{S} / \mathrm{D} \leq 0.8$ [12]. In this paper, $\mathrm{S} / \mathrm{D}=0.8$ was selected for testing, and the geometric dimension of NSCB specimens is shown in Figure 1. In the SCB tests of specimen, the influence of cutting loss of the specimen on tensile strength was considered, and the spacing between support points and specimen diameter $\mathrm{S} / \mathrm{D}=0.8$ was selected referring to previous studies [25].

2.2. Test Equipment and Process. The tensile and fracture tests of semicircular specimens were carried out by using the Shimazu AGS-H5KN precision electronic universal test loading device [11]. The loading was controlled by displacement, and the loading rate was $0.2 \mathrm{~mm} / \mathrm{min}$. During the loading, the load and displacement data system were automatically recorded, and the sampling interval was $0.1 \mathrm{~s}$. The SCB and NSCB specimens were placed on the top of the two supports, respectively, and the support spacing was $4 \mathrm{~cm}$. The damaged specimens were scanned by using the ACTIS5.0-225X-ray Industrial CT testing system to observe the internal crack distribution characteristics.

In the fracture toughness test of $\mathrm{BD}, \mathrm{SCB}$, and NSCB specimens, strain gauges were set at different positions on the surface of specimens for deformation monitoring. Figure 2 shows the specific position and number of strain gauges. In BD specimens, $1 \#-4 \#$ strain gauges were arranged at equal intervals $(6 \mathrm{~mm})$ from the center of the specimen to the lower boundary; in SCB specimens, only one group of strain gauges were set radially at the center of the bottom surface to record the tensile strain changes; in NSCB specimens, two groups of strain gauges were arranged on the line connecting the upper loading point and the notch, the distance between the center of $1 \#$ strain gauge and the loading point was $2 \mathrm{~mm}$, and the distance between the center of $2 \#$ strain gauge and the end of the notch was $1.5 \mathrm{~mm}$. 
TABLe 1: Maceral composition of Datong coal.

\begin{tabular}{lccccccc}
\hline Desmocollinites & Telocollinite & Telinite & Corpocollinite & Semifusinite & Fusinite & Inert detritus & Mineral \\
\hline 2.43 & 42.3 & 14.5 & 0.9 & 14.8 & 10.2 & 3.2 & 11.67 \\
\hline
\end{tabular}

TABLE 2: Parameters of specimens for BD, SCB, and NSCB tests.

\begin{tabular}{|c|c|c|c|c|c|c|}
\hline Mechanical property & Specimen number & $D(\mathrm{~mm})$ & $t(\mathrm{~mm})$ & $M(\mathrm{~g})$ & $a(\mathrm{~mm})$ & $a / R$ \\
\hline \multirow{8}{*}{ Tensile strength } & BD-1 & 49.22 & 25.55 & 63.91 & - & - \\
\hline & $\mathrm{BD}-2$ & 49.22 & 23.79 & 59.44 & - & - \\
\hline & $\mathrm{BD}-3$ & 49.20 & 25.22 & 63.29 & - & - \\
\hline & BD-4 & 49.20 & 24.71 & 59.00 & - & - \\
\hline & SCB-0-1 & 49.13 & 25.13 & 29.45 & 0 & 0 \\
\hline & SCB-0-2 & 48.63 & 24.20 & 26.45 & 0 & 0 \\
\hline & SCB-0-3 & 49.17 & 25.07 & 30.04 & 0 & 0 \\
\hline & SCB-0-4 & 48.49 & 24.28 & 25.67 & 0 & 0 \\
\hline \multirow{12}{*}{ Fracture toughness } & NSCB-4-1 & 48.89 & 25.39 & 28.05 & 4 & 0.16 \\
\hline & NSCB-4-2 & 49.03 & 25.31 & 28.58 & 4 & 0.16 \\
\hline & NSCB-4-3 & 49.08 & 25.55 & 27.96 & 4 & 0.16 \\
\hline & NSCB-4-4 & 48.50 & 24.81 & 26.75 & 4 & 0.16 \\
\hline & NSCB-7-1 & 48.73 & 24.13 & 26.75 & 7 & 0.28 \\
\hline & NSCB-7-2 & 48.63 & 24.20 & 26.21 & 7 & 0.28 \\
\hline & NSCB-7-3 & 49.04 & 25.25 & 27.91 & 7 & 0.28 \\
\hline & NSCB-7-4 & 48.97 & 25.33 & 27.27 & 7 & 0.28 \\
\hline & NSCB-10-1 & 49.03 & 24.79 & 26.86 & 10 & 0.4 \\
\hline & NSCB-10-2 & 49.01 & 25.50 & 28.01 & 10 & 0.4 \\
\hline & NSCB-10-3 & 49.00 & 24.95 & 27.60 & 10 & 0.4 \\
\hline & NSCB-10-4 & 49.02 & 24.77 & 27.80 & 10 & 0.4 \\
\hline
\end{tabular}

$D$ - diameter of the specimen, $t$ - thickness of the specimen, $m$ - mass of the specimen, $a$ - depth of the notch, $a / R$ - dimensionless notch depth.

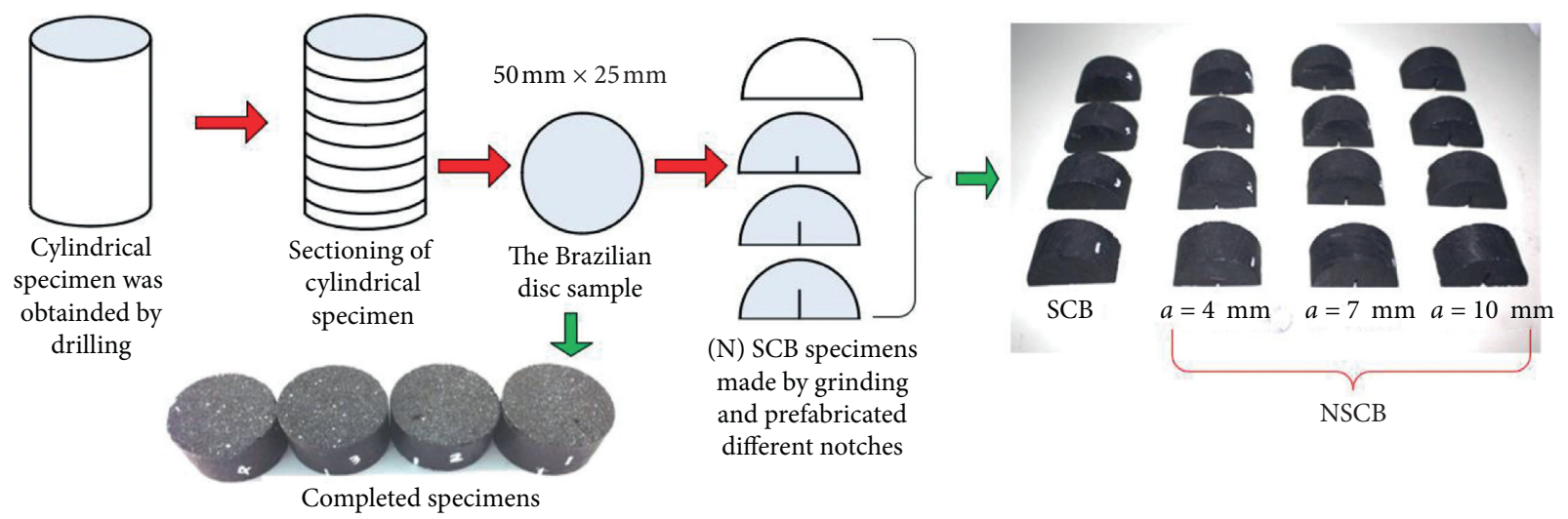

FIGURE 1: Detailed fabrication steps for SCB and NSCB coal specimens. $a$ is the length of the preformed notch.

\section{Tensile Properties of Specimens}

To compare the differences of tensile strength obtained by the BD test and SCB test, 8 specimens in two groups were carried out for BD and SCB tests. The loading-displacement data were recorded during the test, and the strain-time curve was obtained by using strain gauges. After the test, specimens were scanned by CT to analyze the internal fracture characteristics of the specimen.

3.1. BD Test Results. Table 3 shows the peak load, peak displacement, and peak time of four BD specimens. The tensile strength of specimens can be obtained from the following equation:

$$
\sigma_{t}=\frac{2 P_{\max }}{\pi D t}
$$

where $\sigma_{t}$ is the tensile strength, $\mathrm{MPa} ; P_{\max }$ is the ultimate load, $N$; and $D$ and $t$ are the diameter and thickness of specimens, $\mathrm{mm}$. The tensile strength and mean value of specimens can be calculated by the abovementioned equation.

Figure 3 shows the loading-displacement curves of four $\mathrm{BD}$ specimens. It can be found that the peak displacement of four BD specimens is in the range of $0.5-0.8 \mathrm{~mm}$, that is, the specimens fail rapidly after the radial strain reaches $1 \%-$ $1.6 \%$. The average tensile strength of the $\mathrm{BD}$ specimen is $1.749 \mathrm{MPa}$, and the dispersion coefficient is 0.18 . Figure 4 


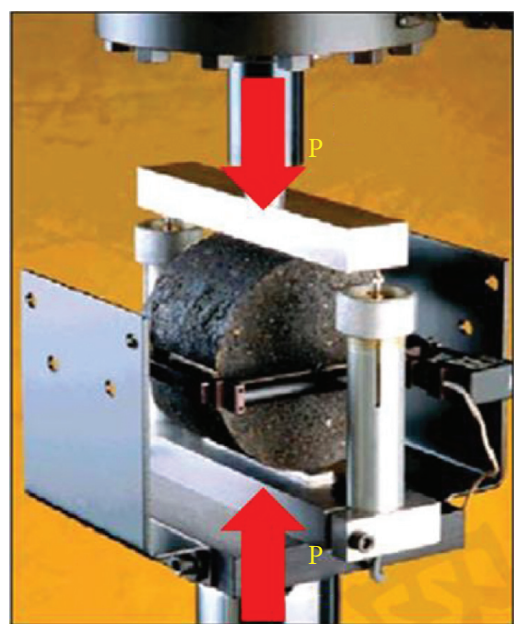

(a)

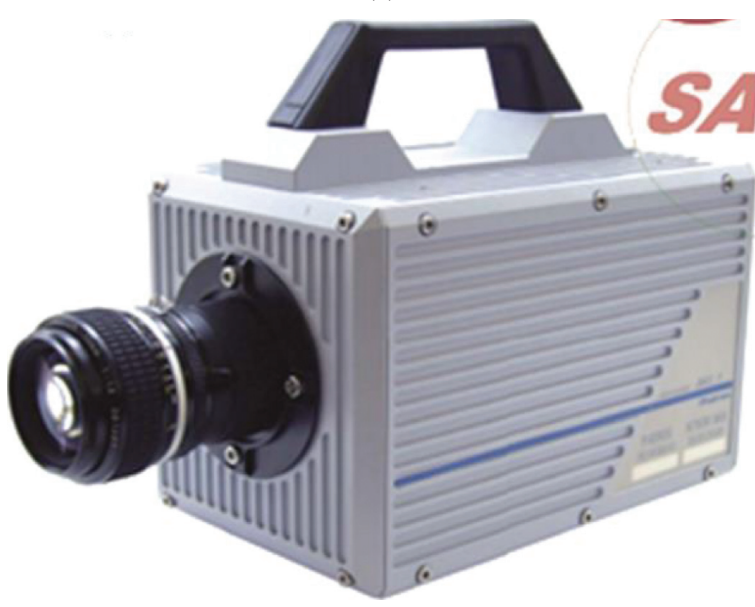

(c)

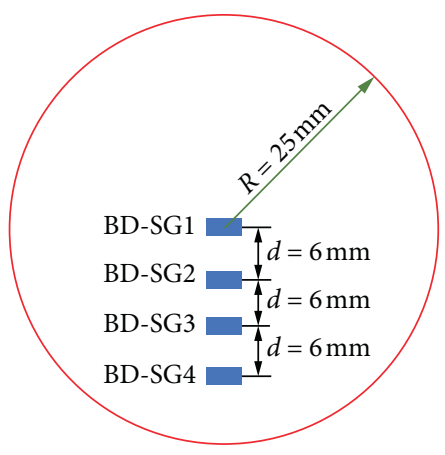

(e)

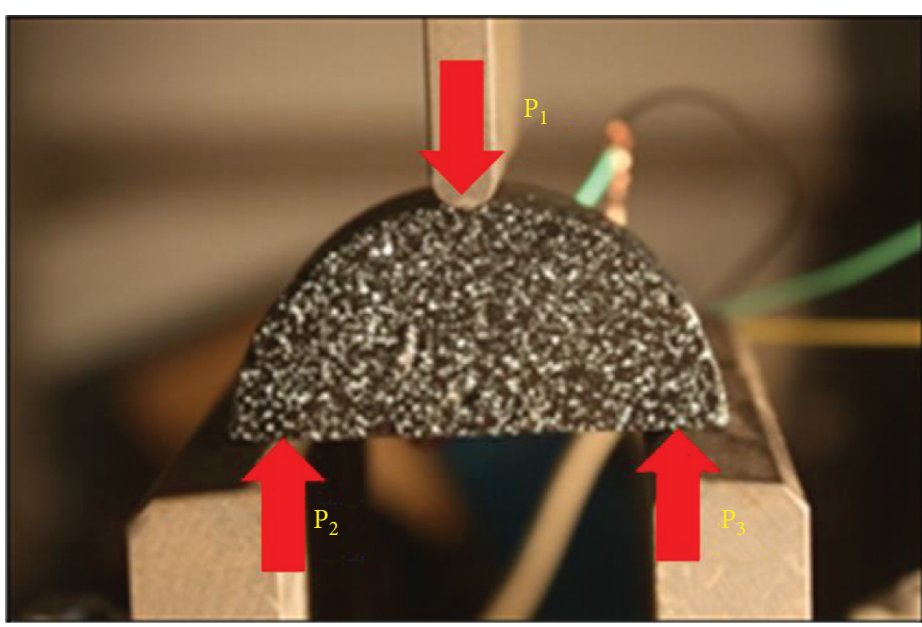

(b)

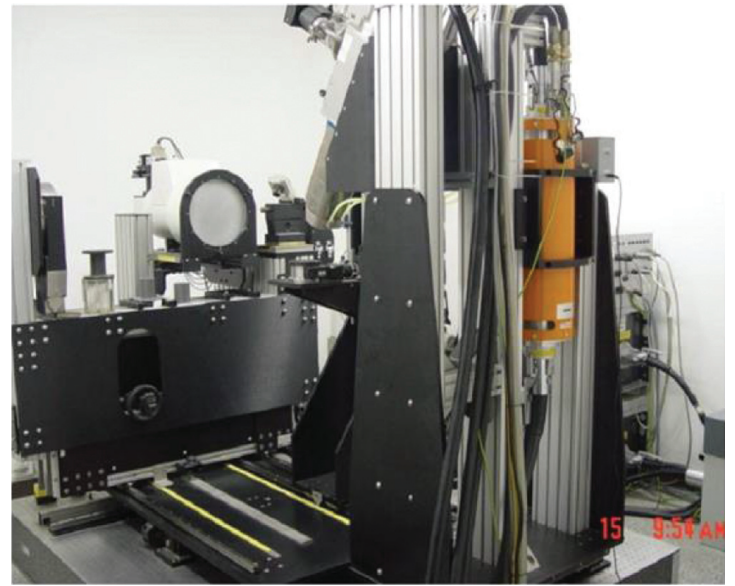

(d)

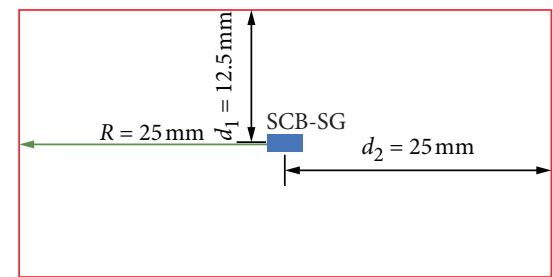

(f)

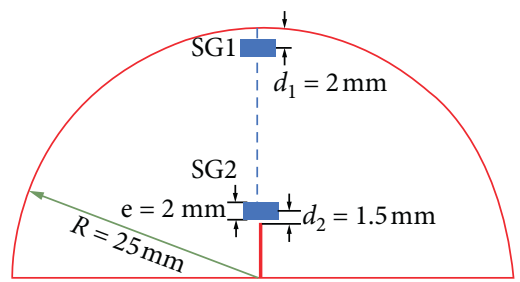

(g)

Figure 2: The loading diagram of the specimen and the position of the strain gauge. (a) Brazilian disc splitting test. (b) Loading diagram of the (N) SCB sample. (c) FASTCAM SA1.1 model 675K-C1 high-speed camera. (d) ACTIS5.0-225 X-ray Industrial CT equipment. (e), (f), and (g) The layout diagrams of strain gauges for Brazilian disc, SCB, and NSCB samples, respectively. 
TABLE 3: Statistics of tensile strength test results.

\begin{tabular}{lcccc}
\hline Specimen number & Peak load $(N)$ & Peak displacement $(\mathrm{mm})$ & Failure time $(\mathrm{s})$ & Tensile strength $(\mathrm{MPa})$ \\
\hline BD-1 & 3692 & 0.704 & 87.5 & 1.87 \\
BD-2 & 2717 & 0.498 & 62.5 & 70.5 \\
BD-3 & 2939 & 0.562 & 95.5 & 1.478 \\
BD-4 & 4081 & 0.781 & 35.9 & 2.138 \\
SCB-0-1 & 648 & 0.261 & 28.1 & 2.612 \\
SCB-0-2 & 465.2 & 0.202 & 42 & 1.967 \\
SCB-0-3 & 329.7 & 0.318 & 35.3 & 1.331 \\
SCB-0-4 & 590.8 & 0.266 & 2.497 \\
\hline
\end{tabular}

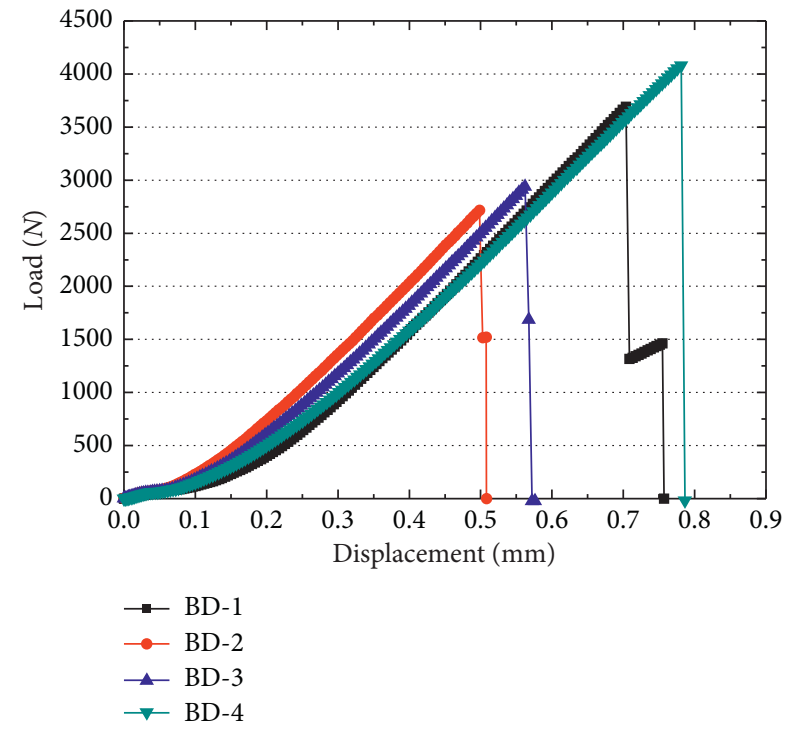

Figure 3: Load-displacement curves of BD coal specimens.

shows the real image and CT scanning image of each specimen after failure. It is found that the main crack of $\mathrm{BD}$ specimens is along the loading direction, but the main crack is not straight due to the influence of specimen heterogeneity. The secondary cracks are propagating in the specimen, and most of them are distributed laterally near the middle region of the specimen.

Figure 5 shows the variation curve of transverse strain at four monitoring points on the surface of $\mathrm{BD}$ specimens with time. The strain near the center of the BD-1 specimen is firstly in tension and then suddenly changes to compression after about $30 \mathrm{~s}$ of loading. This is mainly due to the transverse fracture of the $\mathrm{BD}-1-1$ \# strain gauge and the change of peripheral strain field. Both $\mathrm{BD}-2$ and $\mathrm{BD}-3$ specimens begin to be compressed in the corresponding $1 \#$ strain gauge region and then gradually turn to be in tension. In general, the closer to the bottom of the disc specimen, the greater the tensile strain and strain growth rate. The strain and strain increment of the BD- 4 specimen at $4 \#$ strain gauge are smaller than those of other measuring points. This is mainly due to the abnormal evolution of strain caused by the fracture zone near the $4 \#$ strain gauge at the beginning of loading.

3.2. SCB Test Results. At present, there are many methods to calculate the tensile strength of specimens by the SCB test
[25-28]. In this paper, equation (2) is used to calculate the tensile strength [25]:

$$
\sigma=\frac{4.976 P}{D t}
$$

where $\sigma$ is the tensile strength of the specimen, MPa; $P$ is the ultimate load, $N$; and $D$ and $t$ are the diameter and thickness of the specimen, $\mathrm{mm}$.

Table 3 also shows the peak load, peak displacement, peak time, and tensile strength of four SCB specimens. The average tensile strength measured by the SCB test is $2.102 \mathrm{MPa}$, and the dispersion coefficient is 0.28 . Through the comparison of data in Table 3, it is seen that the tensile strength of the specimen measured by BD tests is 0.83 times of that measured by the SCB method. Previous studies have found that the tensile strength of rock specimens measured by $\mathrm{BD}$ tests is about 0.63 times of that measured by the direct tensile method [29]. Therefore, the tensile strength of specimens measured by SCB tests in this paper is about 0.76 times of that measured by the direct tensile method. In other words, the tensile strength of specimens measured by SCB tests is closer to that measured by the direct tensile test.

Figure 6(a) and 6(b) show loading-displacement curves and bottom transverse strain-time curves of specimens in SCB tests, respectively. Except for the abnormal loadingdisplacement and bottom strain data of the SCB-0-3 specimen, the loading-displacement curves of other specimens are basically the same in terms of development trend. The deformation corresponding to the peak load of the specimen is about $0.2-0.3 \mathrm{~mm}$, which is obviously smaller than the radial peak displacement of BD specimens. The loadingdisplacement curve and strain-time curve show two stages with different growth rates before the peak value. In other words, the initial stress and strain increment are small, but when the deformation is greater than $0.08 \mathrm{~mm}$, the load and strain increase rapidly.

Figure 7 shows the crack distribution on the front of typical specimens after failure in the SCB test. The difference between the loading-displacement curve and bottom straintime curve of SCB-0-3 and the other three specimens is mainly caused by the crack initiation position, which is not near the center of the bottom of the specimen. Therefore, the heterogeneity of coal has a certain influence on the SCB test results.

From the failure load of specimens in the two tests, it is found that, under the same loading rate and specimen thickness, the peak load of specimens in SCB tests is less than 

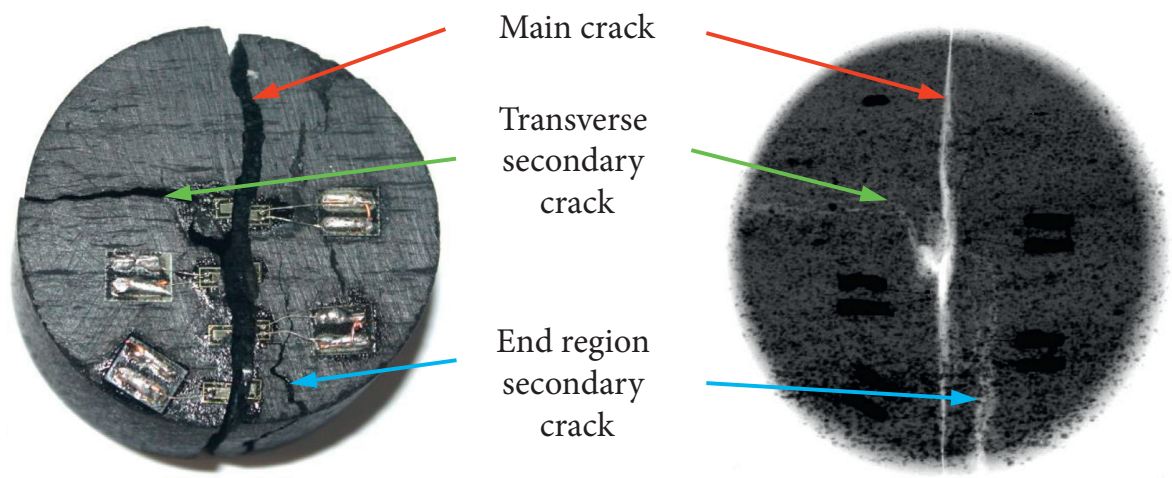

FIGURE 4: CT scanning results of main and secondary cracks in Brazilian disc coal specimens.
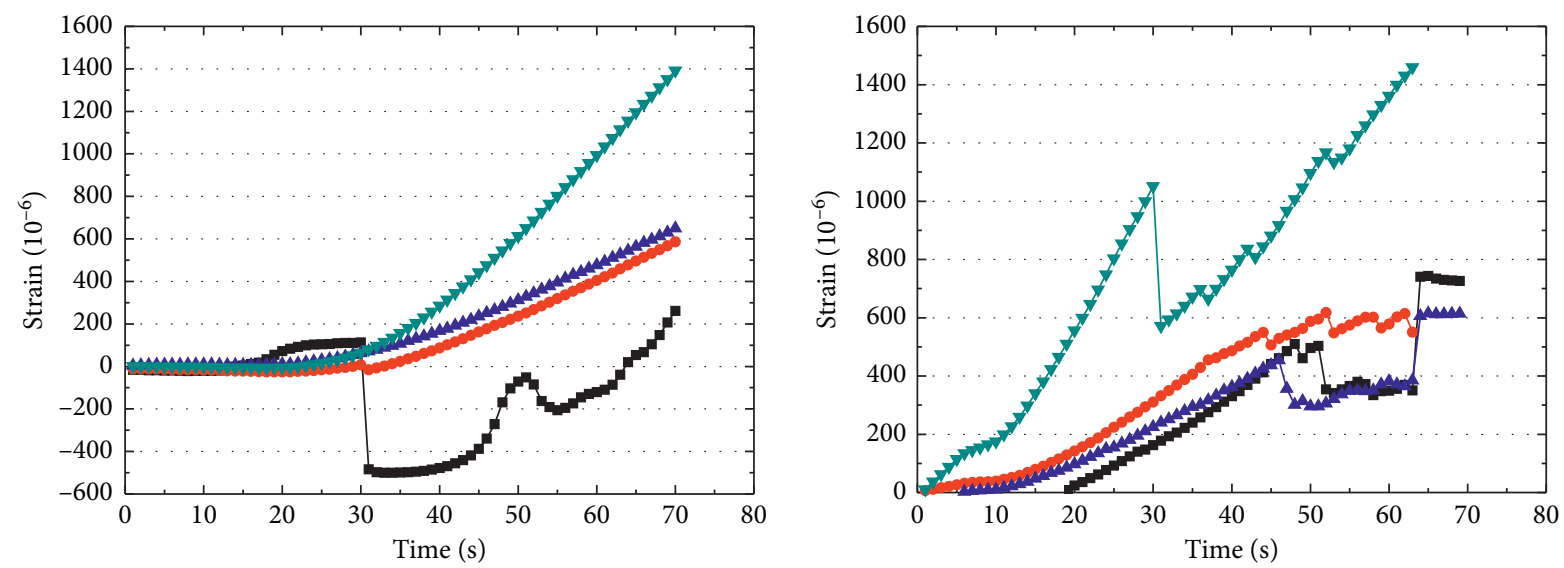

$\rightarrow-\mathrm{BD}-1-1$

$\rightarrow$ BD-2-1

$\rightarrow$ BD-1-2

$\simeq$ BD-1-3

$\rightarrow$ BD-2-2

$\neg$ BD-2-3

$\rightarrow$ BD-1-4

$\rightarrow$ BD-2-4

(a)
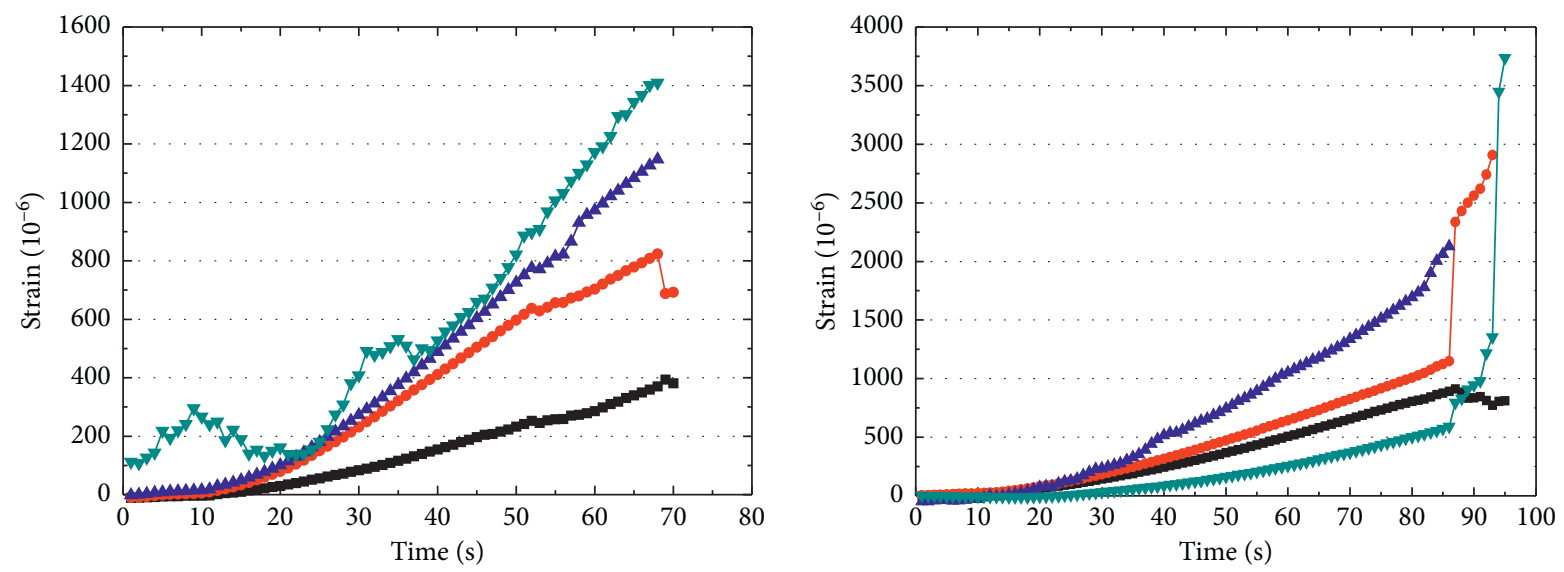

$\rightarrow$ BD-3-1

$\rightarrow-\mathrm{BD}-4-1$

- BD-3-2

$\neg$ BD-3-3

$\rightarrow$ BD-4-2

$\simeq$ BD-4-3

$\rightarrow$ BD-4-4

(c)

(d)

FIGURE 5: Strain-time curves of monitoring points on BD specimens. 


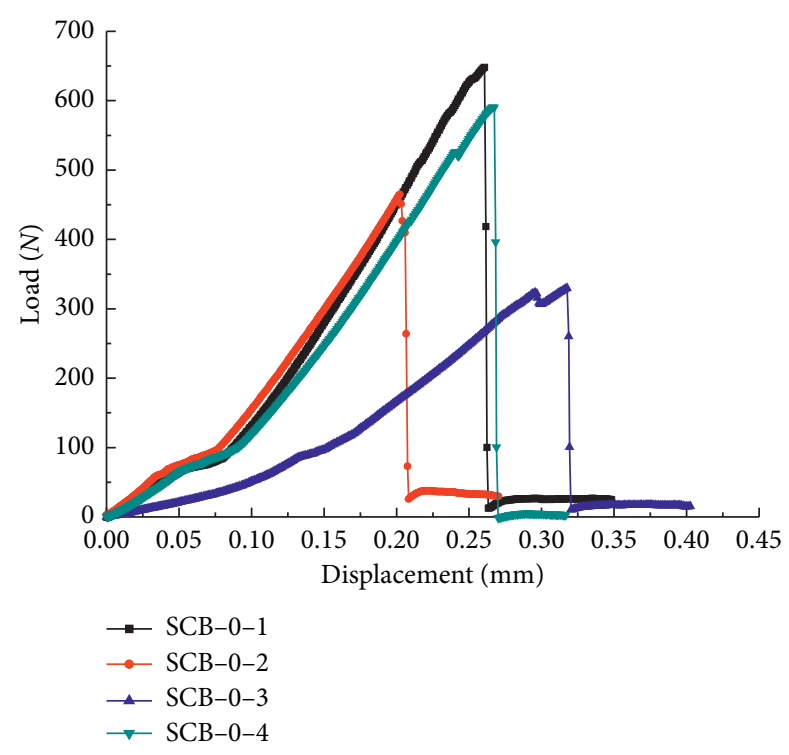

(a)

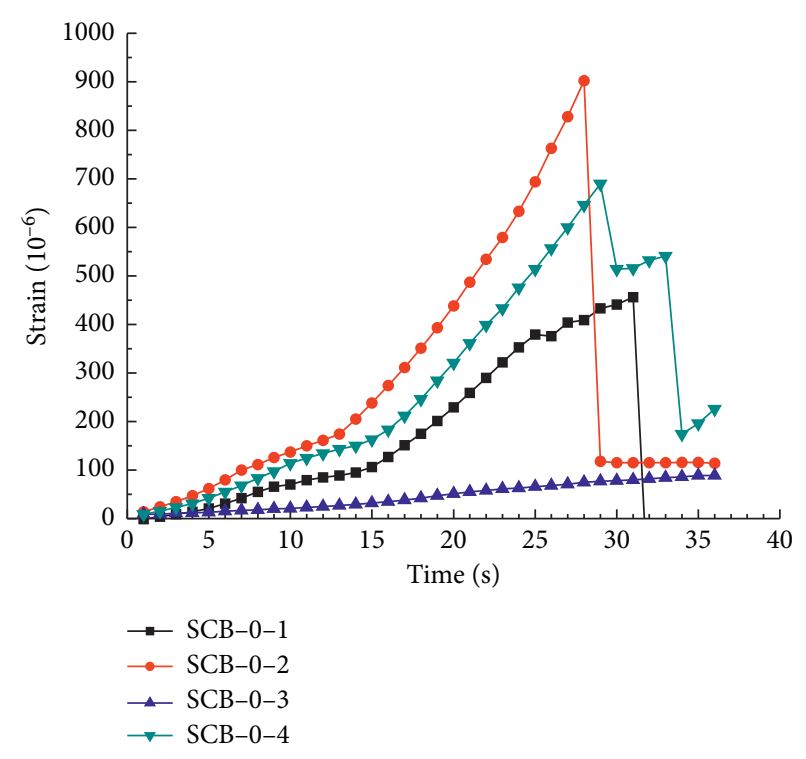

(b)

Figure 6: Curves of (a) load-displacement and (b) strain-time of SCB specimens.

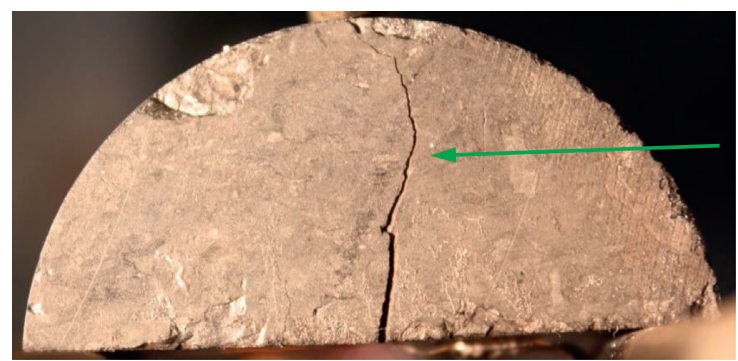

(a)

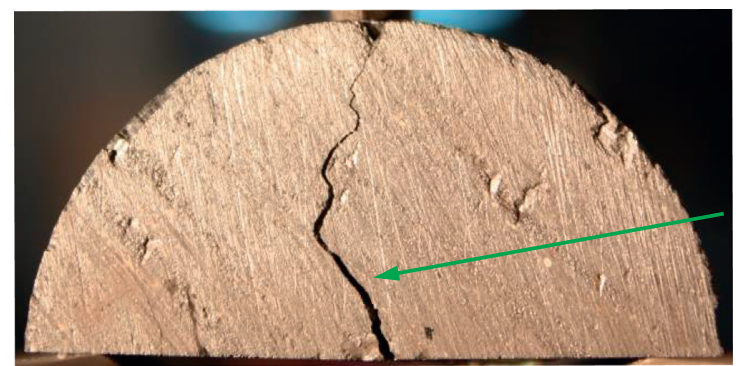

(c)

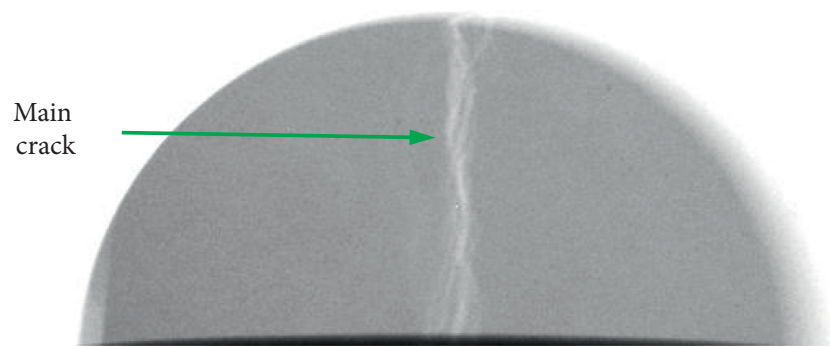

(b)
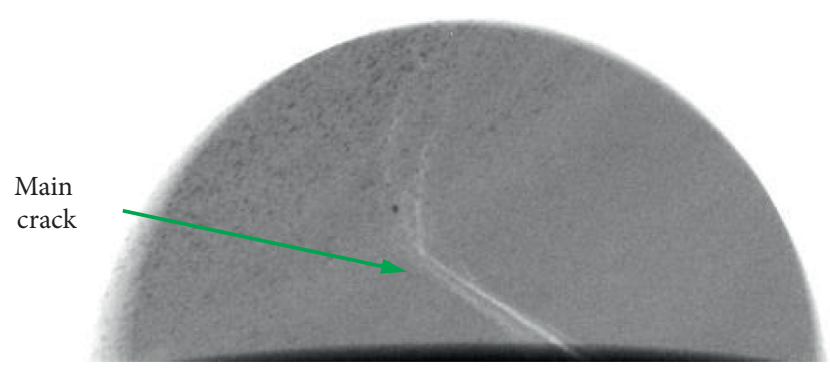

(d)

FIgURE 7: Typical crack distribution and CT image of SCB specimens.

that of specimens in BD tests (about 15.14\%). Therefore, the SCB test can effectively simulate the tensile state of the specimen, and the crack propagation mode in the specimen is simpler; the SCB test is more suitable for measuring the tensile strength of coal.

\section{Fracture Toughness Test of NSCB Specimens}

There were 12 NSCB specimens in 3 groups for the fracture toughness test, namely, 4 specimens with notch depths of $4 \mathrm{~mm}, 7 \mathrm{~mm}$, and $10 \mathrm{~mm}$. Table 2 shows the specific parameters. The test results of 11 specimens were obtained (the results of the NSCB-10-4 specimen were not obtained). Figure 8 shows the loading-displacement curve of NSCB specimens with different notch depths in three groups during the fracture toughness test. With the increase in the notch depth, the average peak load of the specimen decreases. The average peak load of the specimen with the notch depth of $4 \mathrm{~mm}, 7 \mathrm{~mm}$, and $10 \mathrm{~mm}$ are $554 \mathrm{~N}, 363 \mathrm{~N}$, and $255 \mathrm{~N}$, and the corresponding dispersion coefficients are $0.32,0.26$, and 0.35 , respectively, as shown in Table 4 . The variation trend of these curves is similar, that is, they all increase rapidly before the peak load, then slow down, and then, increase rapidly when the displacement of the loading 


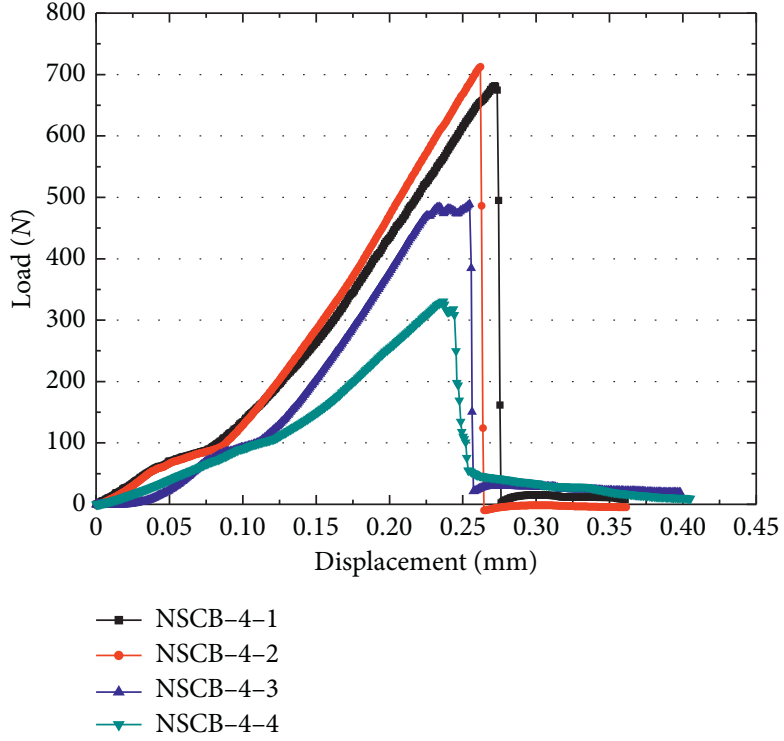

(a)

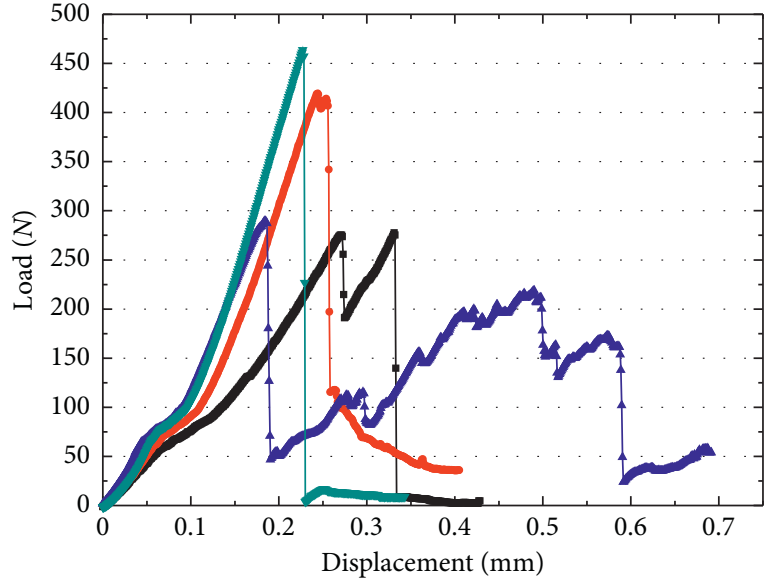

$\rightarrow$ NSCB-7-1

$\rightarrow$ NSCB-7-2

$\simeq$ NSCB-7-3

$\rightarrow$ NSCB-7-4

(b)

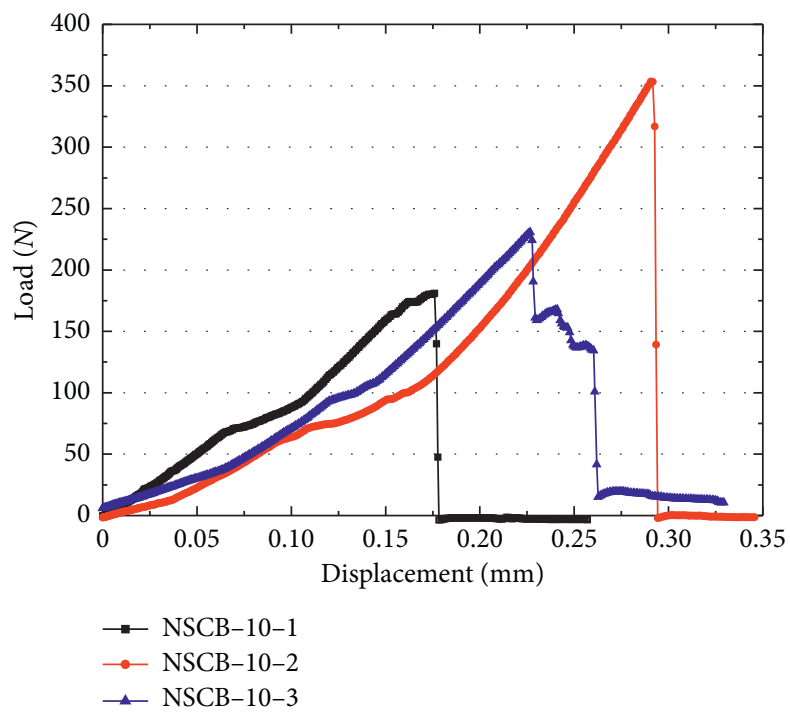

(c)

Figure 8: Load-displacement curves of the NSCB test. (a) $a=4 \mathrm{~mm}$. (b) $a=7 \mathrm{~mm}$. (c) $a=10 \mathrm{~mm}$.

point reaches about $0.1 \mathrm{~mm}$. Affected by the heterogeneity of coal and the difference of notch depth, the loading-displacement curve and surface strain change of specimens with different notch depths are also different. Figure 9 shows the change of strain at two monitoring points on the surface of three groups of NSCB specimens with different notch depths. It can be found that, with the increase in the notch depth, the strain near the loading point changes from compressive strain to tensile strain, while most of strain is still in the tensile state above the crack end.

At present, the commonly used equation for calculating plane strain fracture toughness $K_{\mathrm{IC}}$ of NSCB specimens is as follows [16]:

$$
\begin{aligned}
K_{\mathrm{IC}}= & \frac{Y^{\prime} P_{\max } \sqrt{\pi a}}{2 R t}, \\
Y^{\prime}= & -1.297+9.516\left(\frac{s}{2 R}\right) \\
& -\left(0.47+16.457\left(\frac{s}{2 R}\right)\right) \beta+\left(1.071+34.401\left(\frac{s}{2 R}\right)\right) \beta^{2},
\end{aligned}
$$

where the dimensionless notch depth is $\beta=(a / R)$ and $R$ is the specimen radius, $\mathrm{mm} . P_{\max }$ is the peak load of specimen failure, $\mathrm{N} ; Y^{\prime}$ is the dimensionless stress intensity factor. In 
TABLE 4: Results of mode I fracture toughness of the NSCB specimens.

\begin{tabular}{lccccc}
\hline $\begin{array}{l}\text { Specimen } \\
\text { number }\end{array}$ & $\begin{array}{c}\text { Peak load } \\
(N)\end{array}$ & $\begin{array}{c}\text { Peak displacement } \\
(\mathrm{mm})\end{array}$ & $\begin{array}{c}\text { Dimensionless stress intensity } \\
\text { factor } Y^{\prime}\end{array}$ & $\begin{array}{c}\text { Fracture energy } \\
\left(10^{-3} \mathrm{~J}\right)\end{array}$ & $\begin{array}{c}\text { Fracture energy per thickness } \\
\left(10^{-3} \mathrm{~J} \cdot \mathrm{mm}^{-1}\right)\end{array}$ \\
\hline NSCB-4-1 & 681.85 & 0.271 & 4.87 & 73.9244 & 2.9115 \\
NSCB-4-2 & 712.95 & 0.262 & 4.87 & 71.8900 & 2.8403 \\
NSCB-4-3 & 488.75 & 0.254 & 4.87 & 49.4639 & 1.9359 \\
NSCB-4-4 & 330.75 & 0.237 & 4.87 & 30.7079 & 1.2377 \\
NSCB-7-1 & 277.75 & 0.331 & 4.74 & 45.7862 & 1.8974 \\
NSCB-7-2 & 419.5 & 0.244 & 4.74 & 43.1627 & 1.7835 \\
NSCB-7-3 & 289.45 & 0.184 & 4.74 & 23.6756 & 0.9376 \\
NSCB-7-4 & 463.65 & 0.227 & 4.74 & 40.1110 & 1.5835 \\
NSCB-10-1 & 180.95 & 0.176 & 5.44 & 15.2379 & 0.6146 \\
NSCB-10-2 & 353.55 & 0.290 & 5.44 & 34.7799 & 1.3639 \\
NSCB-10-3 & 230.75 & 0.226 & 5.44 & 21.1605 & 0.8481 \\
\hline
\end{tabular}

general, the plane strain fracture toughness of coal measured by the NSCB test decreases with the increase of notch depth. If $\beta=0.16$, the standard deviation of $K_{\text {IC }}$ is 2.11 , which is significantly higher than that of 1.45 and 1.71 if $\beta=0.28$ and $\beta=0.40$. This also confirms the conclusion of previous studies that the fracture toughness test of NSCB specimens will produce relatively large error if $\beta<0.2$ [12].

The crack growth is affected by the notch depth and the bedding angle. When the notch depth is $4 \mathrm{~mm}$, the crack propagation is easily affected by the bedding; when the notch depth is $7 \mathrm{~mm}$ and $10 \mathrm{~mm}$, the crack propagation is approximately linear and is less affected by the bedding. Figure 10 shows the relationship between $K_{\text {IC }}$ measured by the fracture toughness test of NSCB specimens and notch depth. It is seen that the depth of notch depth also has a certain influence on the dispersion of plane strain fracture toughness of specimens. By fitting the upper boundary, lower boundary, and median value of $K_{\text {IC }}$ data with the change of notch depth $a$, the following equation can be obtained.

The upper boundary fitting curve is

$$
K_{\mathrm{IC}}^{\prime}=14.9028-1.6929 a+0.1056 a^{2} .
$$

The lower boundary fitting curve is

$$
K_{\mathrm{IC}}^{\prime \prime}=2.4046+0.814 a-0.0605 a^{2} .
$$

The fitting curve of average value is

$$
K_{\text {IC }}^{\prime \prime \prime}=8.55333-0.23667 a \text {. }
$$

The results show that the $K_{\mathrm{IC}}$ variation of NSCB specimens with the notch depth shows a V-shaped feature, that is, when the notch depth is $7 \mathrm{~mm}$, the dispersion of the plane strain fracture toughness test value is small.

In the 1960 s, Rice put forward J-integral theory as the basic index to describe the elastic-plastic fracture parameters of materials. Subsequently, Liu et al. established relevant criteria to replace the stress intensity factor. The main advantages of J-integral theory are as follows: (1) due to the conservation property of $J$-integral [30], the specific calculation of stress and displacement near the crack tip is not involved, thus avoiding the tedious process of solving the stress field; (2) the influence of the high-stress gradient region near the crack tip is much smaller than that of the stress intensity factor method on the calculation accuracy of $J$-integral $[16,31]$. Therefore, it is more reasonable to use the theory of elastic-plastic fracture mechanics to evaluate the fracture properties of specimens with cracks.

For mode I fracture of brittle materials, the $J$-integral fracture toughness is [30]

$$
J_{\mathrm{IC}}=\left(\frac{U_{1}}{t_{1}}-\frac{U_{2}}{t_{2}}\right) \frac{1}{a_{2}-a_{1}},
$$

where $U$ is the fracture energy of the specimen, $10^{-3} \mathrm{~J}$.

Generally, the $J$-integral fracture toughness can be measured by only two specimens with different notch depths. In this paper, the $J$-integral fracture toughness is determined by the mean value of the test results of three specimens with different notch depths. Firstly, the fracture energy can be obtained by integrating the loading-displacement curves, and then, the $J$-integral fracture toughness of the specimen can be calculated according to equation (7).

Figure 11 shows the energy absorbed by NSCB specimens with different notch depths during failure. The energy absorbed by the specimen with the small notch depth is greater than that of the specimen with small notch depth. The fracture energy per unit thickness decreases by $0.65 \times 10^{-3} \mathrm{~J} / \mathrm{mm}$ with the increase of $3 \mathrm{~mm}$ of notch depth. The dispersion coefficients of fracture energy per unit thickness of NSCB specimens with notch depths of 4,7 , and $10 \mathrm{~mm}$ are $0.36,0.28$, and 0.41 , respectively. When the notch depth is $7 \mathrm{~mm}$, the dispersion of plane strain fracture toughness and fracture energy per unit thickness is the smallest. Due to the limited number of specimens, further research is needed to determine the relationship between $\beta$ and the discreteness of plane strain fracture toughness.

By fitting the upper limit, lower limit and average value of fracture energy per unit thickness in Figure 11, the relationship between fracture energy per unit thickness and notch depth of specimen can be obtained.

The upper boundary fitting curve is

$$
\frac{U}{t}=4.95986-0.62501 a+0.02641 a^{2} \text {. }
$$

The lower boundary fitting curve is 

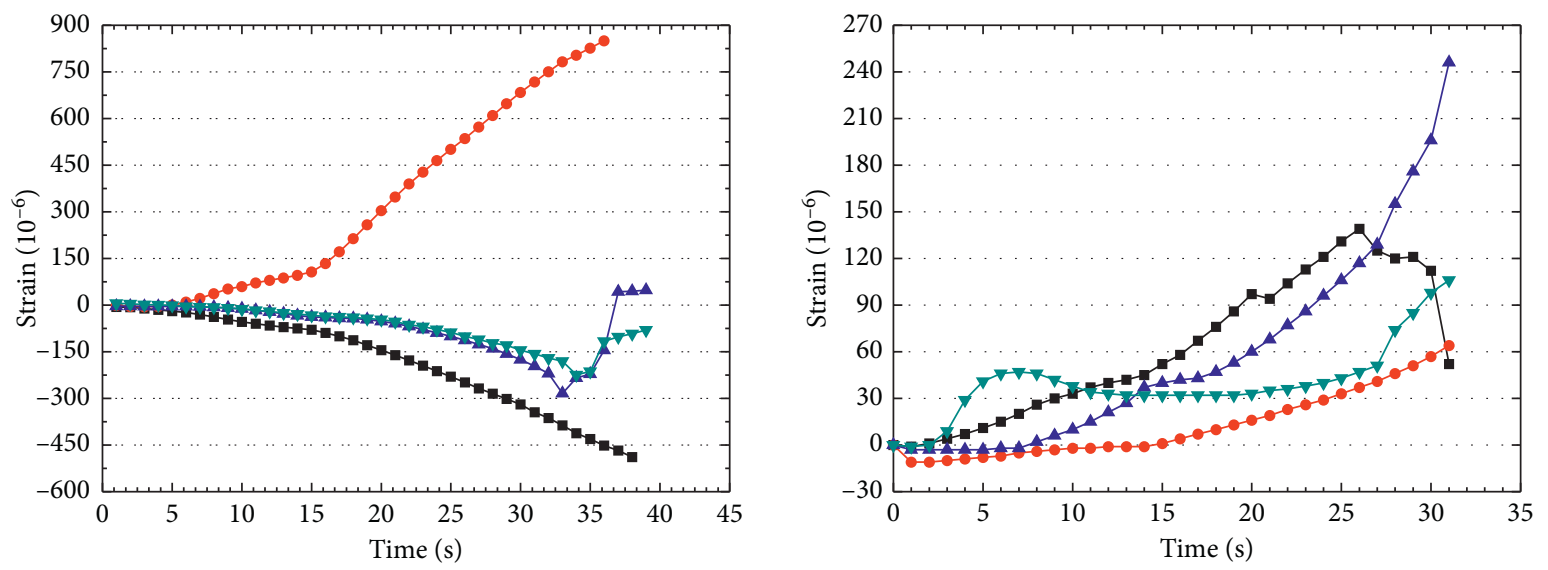

- NSCB-4-1-1

- NSCB-4-1-2

$\rightarrow$ NSCB-4-2-1

$\neg$ NSCB-4-3-1

$\rightarrow$ NSCB-4-2-2

$\rightarrow$ NSCB-4-3-2

$\rightarrow$ NSCB-4-4-1

$\rightarrow$ NSCB-4-4-2

(a)
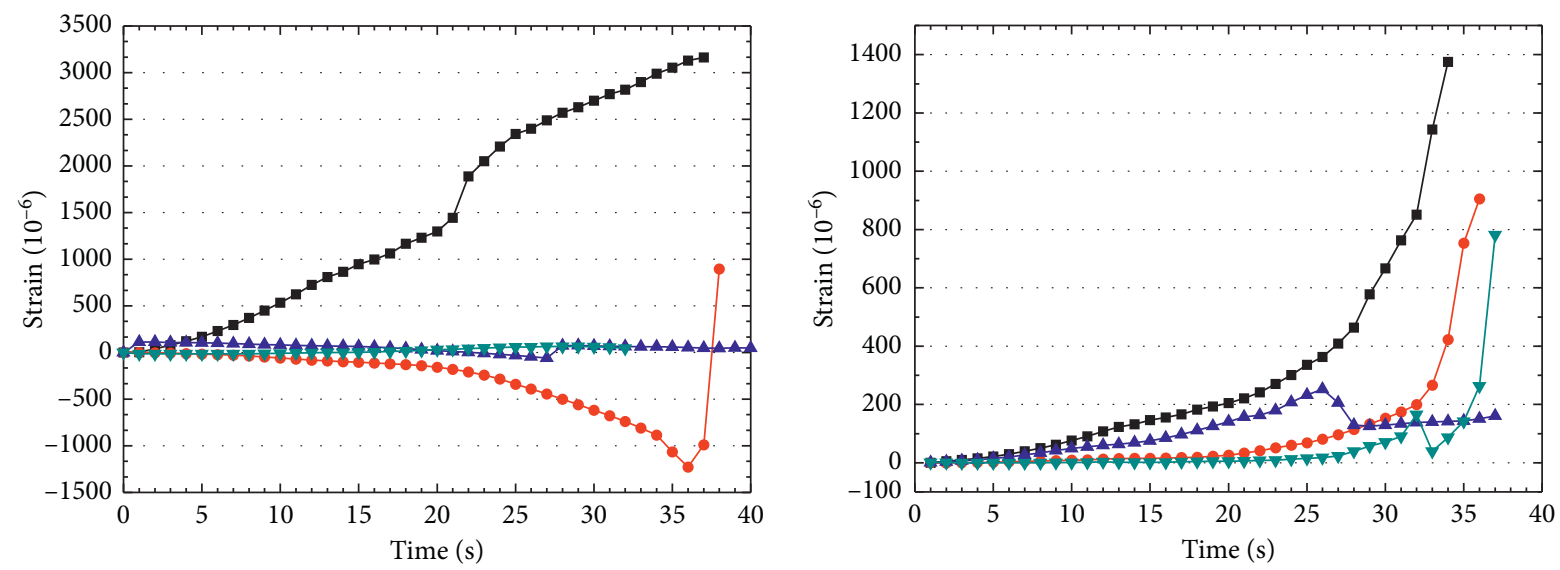

- NSCB-7-1-1

$\rightarrow$ NSCB-7-1-2

- NSCB-7-2-2

$\_$NSCB-7-3-2

$\multimap$ NSCB-7-4-2

(c)

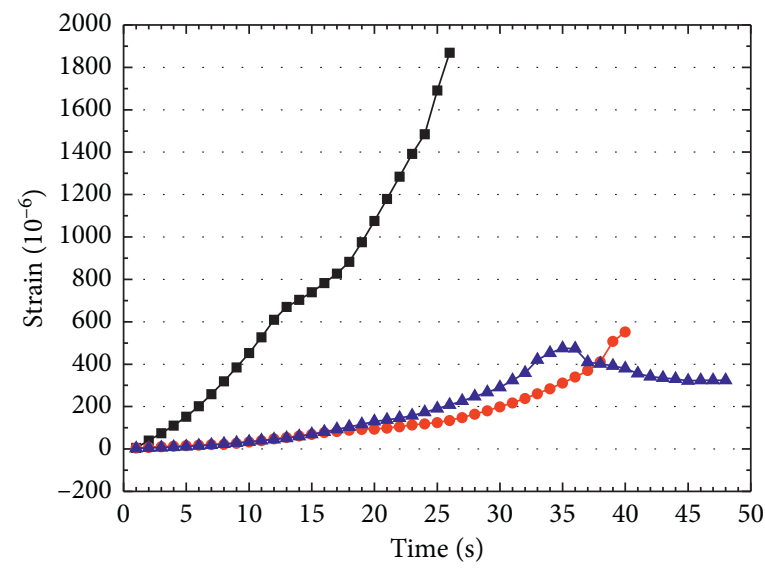

- NSCB-10-1-1

$\rightarrow$ NSCB-10-2-1

$\simeq$ NSCB-10-3-1

(e)

(d)

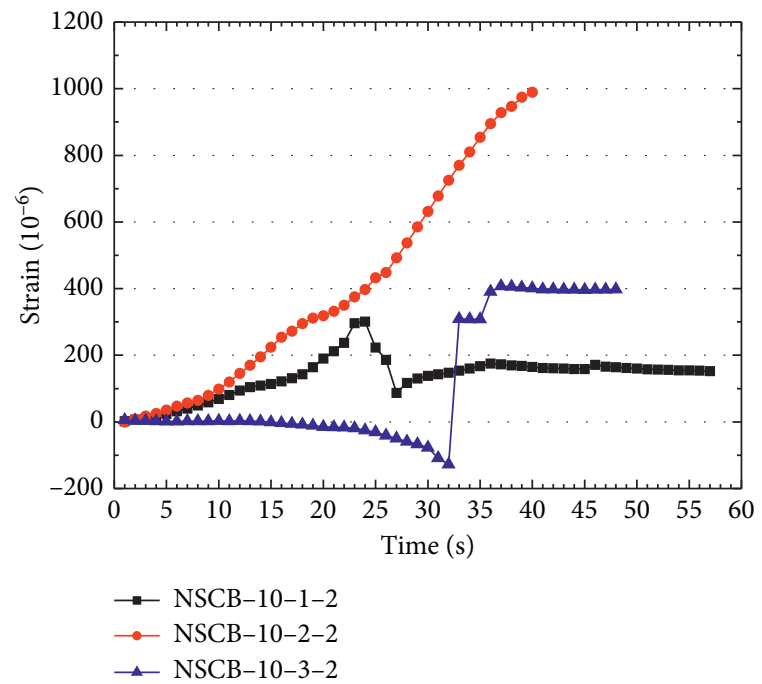

(f)

FIgURe 9: Strain-time curves of monitoring sites on NSCB specimens. (a), (c), and (e) The results of monitoring point 1. (b), (d), and (f) The results of monitoring point 2 . 


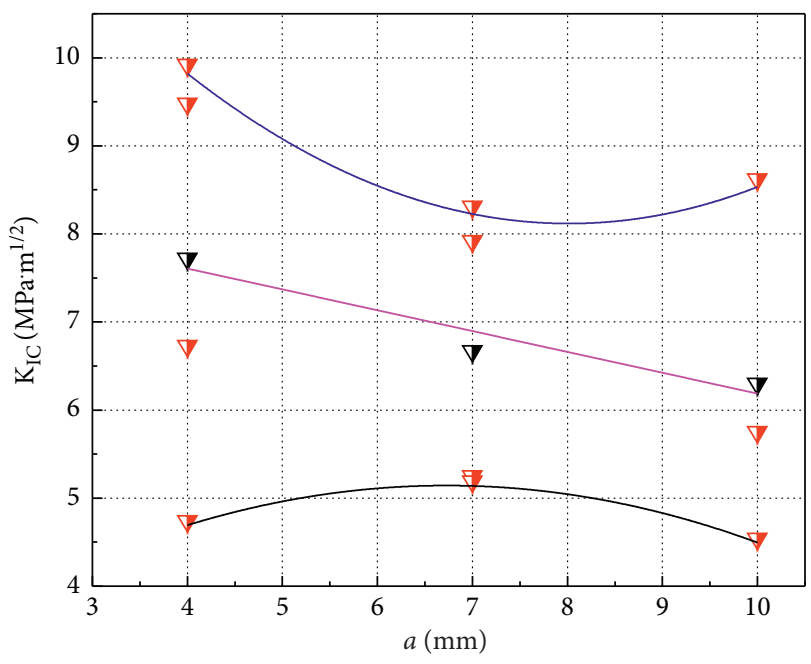

$\nabla$ Average value of fracture toughness

- Fitting curve of upper boundary

— Fitting curve of lower boundary

_ Fitting curve of average boundary

FIGURE 10: Fracture toughness of NSCB specimens with different notch depths.

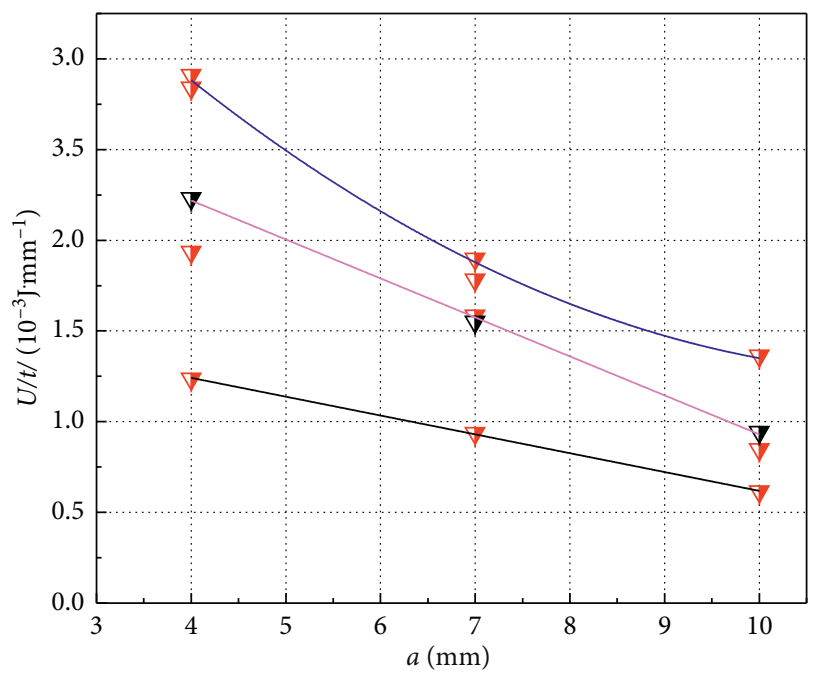

$\nabla$ Average value of fracture energy per thickness

- Upper boundary fitting curve

— Lower boundary fitting curve

_ Fitting curve of average value

FIGURE 11: Fracture energy per thickness of NSCB specimens with different notch depths.

$$
\frac{U}{t}=1.65697-0.10383 a \text {. }
$$

The fitting curve of average value is

$$
\frac{U}{t}=3.0787-0.2148 a \text {. }
$$

The absolute value of the slope of the average fitting curve is the $J$-integral fracture toughness of the specimen in the test. The J-integral fracture toughness value of the specimen is $0.215 \mathrm{KJ} / \mathrm{m}^{2}$, while that of the asphalt mixture material is $1.5-3.0 \mathrm{KJ} / \mathrm{m}[31,32]$. The large difference of the two values indicates that the specimen is brittle and the cohesive force between particles is small [33]. At the same time, the two J-integral fracture toughness values obtained from specimens with three kinds of notch depth have little difference. Therefore, $J$-integral fracture toughness can be used to evaluate the fracture properties of coal more effectively.

\section{Conclusions}

(1) Compared with $\mathrm{BD}$ tests, the tensile strength measured by SCB tests is about 0.76 times of that measured by the direct tensile test, and it is closer to the result of the direct tensile test. Besides, the corresponding deformation of SCB specimens under peak load is about $0.2-0.3 \mathrm{~mm}$, which is significantly less than the corresponding radial displacement $(0.5-0.8 \mathrm{~mm})$ of BD specimens under peak load. Before the peak load, the stress and strain of SCB specimens show two stages of different growth rates. In other words, the initial stress and strain increment are small, but when the deformation is greater than $0.08 \mathrm{~mm}$, the load and strain increase rapidly.

(2) Under the same loading rate and specimen thickness, the peak load of the SCB test is less than that of the BD test by $15.14 \%$. Therefore, the SCB test can effectively simulate the tensile state of specimen, and the crack propagation mode in the specimen is simpler; the SCB test is more suitable for measuring the tensile strength of coal.

(3) With the increase in notch depth, the average peak load and plane strain fracture toughness of the NSCB specimen decrease continuously, and the strain near the loading point of specimen gradually changes from compressive strain to tension strain, while most of them are in tension above the crack end. If $\beta<0.2$, the dispersion of $K_{\mathrm{IC}}$ value of plane strain fracture toughness is larger; while if $\beta=0.28$, the dispersion of $K_{\mathrm{IC}}$ value of specimens is the smallest.

(4) The plane strain fracture toughness $K_{\text {IC }}$ values of the tested specimens are $6.30-7.72 \mathrm{MPa} \sqrt{m}$, and the average $J$-integral fracture toughness is $0.215 \mathrm{KJ} / \mathrm{m}^{2}$. The plane strain fracture toughness $K_{\text {IC }}$ of coal is obviously affected by the notch depth and the dimensionless stress intensity factor $Y^{\prime}$, while the $J$ integral fracture toughness calculation method is simple. The J-integral fracture toughness calculated by different notch depths has little change. Therefore, the $J$-integral fracture toughness can be used to effectively evaluate the fracture properties of coal rock and other brittle materials.

\section{Data Availability}

The data used to support the findings of this study are available from the corresponding author upon request. 


\section{Conflicts of Interest}

The authors declare that they have no conflicts of interest.

\section{Acknowledgments}

This work was financially supported by the research fund of the National Natural Science Foundation of China (51604093), the Fundamental Research Funds for the Universities of Henan Province (Grant no. NSFRF200332), the Henan Key Laboratory for Green and Efficient Mining and Comprehensive Utilization of Mineral Resources (Henan Polytechnic University) (KCF201804), the Key Scientific Research Project Fund of Colleges and Universities of Henan Province (21A610005 and 20B440001), and the Doctoral Foundation of Henan Polytechnic University (B2019-22). All support is greatly appreciated.

\section{References}

[1] D. Ma, J. X. Zhang, H. Y. Duan et al., "Reutilization of gangue wastes in underground backfilling mining: overburden aquifer protection," Chemosphere, vol. 264, no. 1, Article ID 128400, 2021.

[2] D. Ma, H. Duan, Q. Zhang et al., "A numerical gas fracturing model of coupled thermal, flowing and mechanical effects," Computers, Materials \& Continua, vol. 65, no. 3, pp. 21232141, 2020.

[3] J. W. Wu and L. H. Yan, "Comparison study on two kinds of indirect measurement methods of tensile strength of coal in lab," Chinese Journal of Rock Mechanics and Engineering, vol. 23, no. 10, pp. 1643-1647, 2004.

[4] F. Dai, M. D. Wei, N. W. Xu, T. Zhao, and Y. Xu, "Numerical investigation of the progressive fracture mechanisms of four ISRM-suggested specimens for determining the mode I fracture toughness of rocks," Computers and Geotechnics, vol. 69, pp. 424-441, 2015.

[5] J. Zhang, F. Jiang, J. Yang, W. Bai, and L. Zhang, "Rockburst mechanism in soft coal seam within deep coal mines," International Journal of Mining Science and Technology, vol. 27, no. 3, pp. 551-556, 2017.

[6] J. F. Zhang, D. Li, and Y. H. Wang, "Predicting tunnel squeezing using a hybrid classifier ensemble with incomplete data," Bulletin of Engineering Geology and the Environment, vol. 79, no. 6, pp. 1-12, 2020.

[7] D. Ma, H. Duan, W. Liu, X. Ma, and M. Tao, "Water-sediment two-phase flow inrush hazard in rock fractures of overburden strata during coal mining," Mine Water and the Environment, vol. 39, no. 2, pp. 308-319, 2020.

[8] D. Ma, H. Duan, X. Li, Z. Li, Z. Zhou, and T. Li, "Effects of seepage-induced erosion on nonlinear hydraulic properties of broken red sandstones," Tunnelling and Underground Space Technology, vol. 91, p. 102993, 2019.

[9] M. F. Cai, M. C. He, and D. Y. Liu, Rock Mechanics and Engineering, pp. 31-50, Science Press, Beijing, China, 2013.

[10] M. C. He, J. C. Hu, X. Wei et al., "Splitting test and analysis of rock tensile strength," Ming Research and Development, vol. 25, no. 2, pp. 12-16, 2005.

[11] S. Gong, Z. Wang, L. Zhou et al., "Influence of cyclic impact loading and axial stress on dynamic mechanical properties of burst-prone coal," Shock and Vibration, vol. 2021, Article ID 6649308, 10 pages, 2021.
[12] M. D. Kuruppu, Y. Obara, M. R. Ayatollahi, K. P. Chong, and T. Funatsu, "ISRM-suggested method for determining the mode I static fracture toughness using semi-circular bend specimen," Rock Mechanics and Rock Engineering, vol. 47, no. 1, pp. 267-274, 2014.

[13] R. J. Fowell, "Suggested method for determining mode I fracture toughness using Cracked Chevron Notched Brazilian Disc (CCNBD) specimens," International Journal of Rock Mechanics and Mining Sciences \& Geomechanics Abstracts, vol. 32, no. 1, pp. 57-64, 1995.

[14] M. J. Iqbal and B. Mohanty, "Experimental calibration of ISRM suggested fracture toughness measurement techniques in selected brittle rocks," Rock Mechanics and Rock Engineering, vol. 40, no. 5, pp. 453-475, 2007.

[15] M. D. Kuruppu and K. P. Chong, "Fracture toughness testing of brittle materials using semi-circular bend (SCB) specimen," Engineering Fracture Mechanics, vol. 91, pp. 133-150, 2012.

[16] X.-J. Li and M. O. Marasteanu, "Using semi circular bending test to evaluate low temperature fracture resistance for asphalt concrete," Experimental Mechanics, vol. 50, no. 7, pp. 867-876, 2010.

[17] F. Pérez-Jiménez, R. Botella, K.-H. Moon, and M. Marasteanu, "Effect of load application rate and temperature on the fracture energy of asphalt mixtures. Fénix and semi-circular bending tests," Construction and Building Materials, vol. 48, pp. 1067-1071, 2013.

[18] H. F. Azar, N. Choupani, H. Afshin et al., "Effect of mineral admixtures on the mixed-mode (I/II) fracture characterization of cement mortar: CTS, CSTBD and SCB specimens," Engineering Fracture Mechanics, vol. 134, pp. 20-34, 2015.

[19] Q. B. Zhang and J. Zhao, "Effect of loading rate on fracture toughness and failure micromechanisms in marble," Engineering Fracture Mechanics, vol. 102, no. 2, pp. 288-309, 2013.

[20] M. R. M. Aliha and M. R. Ayatollahi, "Mixed mode I/II brittle fracture evaluation of marble using SCB specimen," Procedia Engineering, vol. 10, no. 1, pp. 311-318, 2011.

[21] K. P. Chong and M. D. Kuruppu, "New specimen for fracture toughness determination for rock and other materials," International Journal of Fracture, vol. 26, no. 2, pp. 59-62, 1984.

[22] M. R. M. Aliha, M. Sistaninia, D. J. Smith, M. J. Pavier, and M. R. Ayatollahi, "Geometry effects and statistical analysis of mode I fracture in Guiting limestone," International Journal of Rock Mechanics and Mining Sciences, vol. 51, no. 4, pp. 128-135, 2012.

[23] Y. X. Zhou, K. Xia, X. B. Li et al., "Suggested methods for determining the dynamic strength parameters and mode-I fracture toughness of rock materials," International Journal of Rock Mechanics and Mining Sciences, vol. 49, no. 1, pp. 105-112, 2012.

[24] Y. Liu and X. N. Zhang, "Comparative analysis for semicircle bending strength and indirect tensile strength of asphalt mixtures," Technology of Highway and Transport, vol. 3, pp. 34-37, 2011.

[25] B. S. Huang, X. Shu, and Y. J. Tang, "Comparison of semicircular bending and indirect tensile strength tests for HMA mixtures," Advances in Pavement Engineering, vol. 1, pp. 155-169, 2005.

[26] F. M. Bayomy, M. A. Mullaglan, A. A. Abdo et al., "Evaluation of hot mix asphalt (HMA) fracture resistance using the critical strain energy release rate," in Proceedings of the Transportation Research Board 85th Annual Meeting, pp. 9-14, Transportation Research Board Business Office, Washington, DC, USA, January 2006. 
[27] G. Y. Lv, P. W. Hao, L. G. Peng et al., "Mechanical simulation of semi-circular bending test in asphalt mixtures," Journal of Wuhan University of Technology, vol. 30, no. 3, pp. 50-52, 2008.

[28] X. W. Li, The Mechanical Properties of Rock, pp. 40-43, Coal Industry Press, Beijing, China, 1983.

[29] Q. B. Zhang and J. Zhao, "Quasi-static and dynamic fracture behaviour of rock materials: phenomena and mechanisms," International Journal of Fracture, vol. 189, no. 1, pp. 1-32, 2014.

[30] J. H. Liu, D. Y. Wang, and Y. Liu, "Evaluation asphalt mixture fracture resistance using the J-integral," Chinese Journal of Solid Mechanics, vol. 31, no. 1, pp. 16-22, 2010.

[31] D. T. Yang and H. Zhu, "Contrast test of semi-circular bending to small beam three-point bending for HMA," Journal of Wuhan University of Technology, vol. 34, no. 6, pp. 1224-1227, 2010.

[32] Y. Liu, Research on Dynamic Response and Fracture Performance of Asphalt Mixture Based on Semi-circular Bending Test, Harbin Institute of Technology, Harbin, China, 2009.

[33] S. Gong, Study on Mechanical Characteristics of Dynamic Tensile and Mode I Fracture of Coal Samples under Impact Loading, China University of Mining and Technology, Beijing, China, 2018. 